\title{
Differential expression and clinical significance of three inflammation-related microRNAs in gangliogliomas
}

\author{
A. S. Prabowo ${ }^{1}$, J. van Scheppingen ${ }^{1}$, A. M. Iyer ${ }^{1}$, J. J. Anink' , W. G. M. Spliet ${ }^{3}$, P. C. van Rijen ${ }^{4}$, \\ A. Y. N. Schouten-van Meeteren ${ }^{2}$ and E. Aronica ${ }^{1,5,6^{*}}$
}

\begin{abstract}
Purpose: miR21, miR146, and miR155 represent a trio of microRNAs which has been shown to play a key role in the regulation of immune and inflammatory responses. In the present study, we investigated the differential expression and clinical significance of these three miRNAs in glioneuronal tumors (gangliogliomas, GGs) which are characterized by prominent activation of the innate immune response.

Methods: The expression levels of miR21, miR146, and miR155 were evaluated using Taqman PCR in 34 GGs, including 15 cases with sufficient amount of perilesional cortex. Their expression was correlated with the tumor features and the clinical history of epilepsy. In addition, in situ hybridization was used to evaluate their cellular distribution in both tumor and peritumoral cortex.

Results: Increased expression of miR146a was observed in both tumor and peritumoral cortex compared to control samples. miR146a was detected in both neuronal and astroglial cells. Tumor and peritumoral miR146a expression was negatively correlated with frequency of seizures and the density of activated microglial cells. Neuronal and astroglial expression was observed for both miR21 and miR155 with increased expression of miR21 within the tumor and miR155 in the peritumoral region. Negative correlations were observed between the miRNA levels and the expression of putative targets within the astroglial component of the tumor.

Conclusion: We report a differential regulation of three miRNAs, known to be related to inflammation, in both tumor and peritumoral cortex of patients with GG. Moreover, our findings suggest a functional relationship between miR146a expression and epilepsy, either directly in epileptogenesis or as modulation of seizure activity.
\end{abstract}

Keywords: Gangliogliomas, miRNA, Real-time polymerase chain reactions, In situ hybridization, Immunohistochemistry, Inflammation, Epilepsy

\section{Introduction}

Gangliogliomas (GGs) represent the most frequent tumor entity in young patients who undergo surgery for chronic intractable focal epilepsy [1,2]. They are lowgrade, slowly growing, cortically based tumors included within the group of long-term epilepsy associated tumor (LEAT; [2]). GGs display a very low risk for tumor recurrence and malignant progression. Although surgical

\footnotetext{
* Correspondence: e.aronica@amc.uva.nl

${ }^{1}$ Department of (Neuro)Pathology, Academic Medical Center, University of

Amsterdam, Meibergdreef 9, 1105 AZ Amsterdam, The Netherlands

${ }^{5}$ SEIN - Stichting Epilepsie Instellingen Nederland, Heemstede, The

Netherlands

Full list of author information is available at the end of the article
}

intervention shows favorable prognosis, both in terms of tumor management and improving seizures, in a proportion of cases, seizures may persist despite surgery [1-4]. Resection of tumor alone has been associated with a less satisfactory outcome supporting the epileptogenic contribution of the peritumoral zone [5, 6]. Histologically, GGs are characterized by a mixture of dysmorphic neurons and glial tumor cells. Recent studies have provided evidence of a sustained inflammatory reaction in glioneuronal lesions with activation of both the innate and adaptive immune response and involvement of different inflammatory pathways, including the interleukin-1 receptor/Toll-like receptor pathway (IL-1R/TLR) [7-10]. 
Interestingly, experimental evidence indicates proconvulsant and ictogenic properties of these pathways, supporting the role of inflammation in the pathophysiology of human epilepsy (for review see [11-14]). Accordingly, it has also been shown that the density of activated microglia, as well as the number of IL- $1 \beta$-positive neuronal cells in focal cortical dysplasia (FCD) and in GG was positively correlated with the frequency of seizures prior to surgical resection $[7,15,16]$.

In recent years, microRNAs (miRNAs) have been reported as key post-transcriptional regulators of gene expression in several biological processes of the central nervous system, as well as in the pathogenesis of different neurological diseases and in oncogenesis [17-20]. Recently, both clinical and experimental studies have shown the potential contribution of miRNAs to epilepsy pathophysiology [21, 22]. miRNA array profiling studies point to the role of microRNAs involved in inflammatory processes [23-26]. During epileptogenesis in experimental temporal lobe epilepsy [26], a significant upregulation of miRNAs involved in the regulation of the IL-1R/TLR proinflammatory pathway, including miR146a, miR21, and miR155 [27-32], has been observed. Interestingly, miR146a has been shown to be induced in response to inflammatory cues as a negative-feedback regulator of the human astrocyte-mediated inflammatory response [25].

In the present study, we investigated the expression and cellular distribution of miR21, miR146, and miR155, three miRNAs involved in the regulation of inflammatory pathways with proictogenic properties [30], in a large cohort of gangliogliomas with well-characterized intractable epilepsy. In addition, we analyzed the expression of these miRNAs in the perilesional tissue, which is of particular interest for its possible contribution to generation/propagation of seizures. To provide better insights into the mechanisms underlying the intrinsic and high epileptogenicity of these glioneuronal lesions, we evaluated a possible relationship between changes in expression of these miRNAs, microglial activation, and the clinical course of epilepsy.

\section{Material and methods}

\section{Subjects}

The cases included in this study were obtained from the archives of the Department of Neuropathology of the Academic Medical Center (AMC, University of Amsterdam) and the University Medical Center in Utrecht (UMCU). A total of 34 brain tissue specimens, removed from patients undergoing surgery for intractable epilepsy, were examined. Tissue was obtained and used in accordance with the Declaration of Helsinki and the AMC Research Code provided by the Medical Ethics Committee and approved by the science committee of the UMC Utrecht Biobank. All cases were reviewed independently by two neuropathologists, and the diagnosis was confirmed according to the revised WHO classification of tumors of the central nervous system [33]. Thirty-two patients underwent resection of the tumor for medically intractable epilepsy. The predominant type of seizure pattern was that of complex partial seizures, which were resistant to maximal doses of anti-epileptic drugs (AEDs). The patients with epilepsy underwent presurgical evaluation [34], and the post-operative seizure outcome was classified according to Engel [35]. Twenty patients underwent tailored temporal lobe epilepsy surgery. The clinical features of the included GG patients are summarized in Table 1. We included 15 GGs cases that contained sufficient amount of peritumoral tissue (normalappearing cortex/white matter adjacent to the tumor), for comparison with the autopsy specimens. Control cortex/ white matter from the temporal region was obtained at autopsy from eight adult control patients without history of neurological diseases (years/range, 25-52; female/male (F/M), 4/4). Autopsy brain tissues from patients with neuro-inflammatory pathologies (viral encephalitis; herpes simplex encephalitis and rabies encephalitis) were also examined as positive controls. All autopsies were performed within $12 \mathrm{~h}$ after death. Furthermore, we also used histologically normal temporal neocortex from three male adult patients (F/M, 2/1; years/range, 20-32) undergoing extensive surgical resection of the mesial structures for the treatment of medically intractable complex partial epilepsy.

\section{Tissue preparation}

Brain tissue from the control autopsy patients $(n=8)$ and surgical tissue block from patients with GG were snap frozen in liquid nitrogen and stored at $-80{ }^{\circ} \mathrm{C}$ until further use (RNA isolation for RT-PCR). Additional tissue was fixed in $10 \%$ buffered formalin and embedded in paraffin. Paraffin-embedded tissue was sectioned at $5 \mu \mathrm{m}$, mounted on pre-coated glass slides (Star Frost, Waldemar Knittel $\mathrm{GmbH}$, Brunschweig, Germany), and used for in situ hybridizations and immunocytochemistry, as described below. One representative paraffin block per case were sectioned, stained, and assessed. Sections of all specimens were processed for hematoxylin and eosin (HE), as well as for immunocytochemical stainings for a number of neuronal and glial markers to confirm the diagnosis of ganglioglioma.

\section{In situ hybridization}

In situ hybridization (ISH) for miR21, miR146a, and miR155 were performed using a $5^{\prime}-3^{\prime}$ fluorescein (FAM) and double digoxygenin (DIG)-labeled Superior probes (miR21; DIG-TcaAcaTcaGucTgaTaaGcuA-DIG; miR146a: FAM-AacCcaTggAauTcaGuuCucA; miR155: DIG-AccCcuAucAcgAuuAgcAuuAa-DIG; Ribotask ApS, Odense, Denmark). The hybridizations were done on $5 \mu \mathrm{m}$ sections of paraffin-embedded materials as described 
Table 1 Summary of clinical findings of GGS

\begin{tabular}{|c|c|c|c|c|c|c|c|}
\hline Patient & Gender & Localization & $\begin{array}{l}\text { Age of surgery } \\
\text { (year) }\end{array}$ & $\begin{array}{l}\text { Age of seizure } \\
\text { onset (year) }\end{array}$ & $\begin{array}{l}\text { Duration of } \\
\text { epilepsy (year) }\end{array}$ & $\begin{array}{l}\text { Pre-operative seizure } \\
\text { frequency last month }^{d}\end{array}$ & $\begin{array}{l}\text { Post-operative outcome } \\
\text { (Engel's score) }\end{array}$ \\
\hline $1^{a, c}$ & $F$ & $T$ & 29 & 13 & 16 & 200 & $1 a$ \\
\hline $2^{a, c}$ & M & $\mathrm{T}$ & 19 & 10 & 9 & 20 & $1 a$ \\
\hline $3^{a, c}$ & M & $T$ & 17 & 14 & 3 & 25 & $1 a$ \\
\hline $4^{a, c}$ & $\mathrm{~F}$ & $\mathrm{~T}$ & 11 & 8 & 3 & 56 & $1 a$ \\
\hline $5^{a, c}$ & M & $T$ & 16 & 14 & 2 & 30 & $1 a$ \\
\hline $6^{a, c}$ & M & $T$ & 24 & 1 & 23 & 100 & $1 a$ \\
\hline $7^{a, c}$ & $\mathrm{~F}$ & $\mathrm{~T}$ & 42 & 11 & 31 & 60 & $1 a$ \\
\hline $8^{a, c}$ & M & $T$ & 31 & 12 & 19 & 150 & $1 a$ \\
\hline $9^{a, b, c}$ & M & $T$ & 21 & 13 & 8 & 70 & $2 a$ \\
\hline $10^{a, c}$ & $\mathrm{~F}$ & $\mathrm{~T}$ & 6 & 4 & 2 & 30 & $1 a$ \\
\hline $11^{\mathrm{a}, \mathrm{c}}$ & $\mathrm{F}$ & $\mathrm{T}$ & 14 & 11 & 3 & 55 & $1 a$ \\
\hline $12^{a, c}$ & M & $T$ & 17 & 15 & 2 & 25 & $1 a$ \\
\hline $13^{a, b, c}$ & $\mathrm{~F}$ & P & 24 & 23 & 1 & 3 & $1 b$ \\
\hline $14^{\mathrm{a}, \mathrm{c}}$ & $\mathrm{F}$ & $T$ & 23 & 14 & 9 & 60 & $1 a$ \\
\hline $15^{\mathrm{a}, \mathrm{c}}$ & $\mathrm{F}$ & $\mathrm{T}$ & 19 & 15 & 4 & 70 & $1 a$ \\
\hline $16^{\mathrm{a}}$ & M & $T$ & 18 & 13 & 5 & 20 & $1 a$ \\
\hline $17^{a, b}$ & M & P & 28 & 27 & 1 & 80 & $1 b$ \\
\hline $18^{\mathrm{a}}$ & M & $\mathrm{T}$ & 3 & 1 & 2 & 70 & $1 a$ \\
\hline $19^{a}$ & $\mathrm{~F}$ & $\mathrm{~T}$ & 34 & 11 & 23 & 90 & $1 a$ \\
\hline $20^{a}$ & $F$ & $\mathrm{~T}$ & 0.5 & 1 & 0.5 & 60 & $3 a$ \\
\hline $21^{a}$ & M & $\mathrm{T}$ & 17 & 1 & 16 & 100 & $1 a$ \\
\hline $22^{\mathrm{a}}$ & M & $T$ & 20 & 11 & 9 & 160 & $1 a$ \\
\hline $23^{\mathrm{a}}$ & F & $\mathrm{Fr}$ & 2 & 0.25 & 2 & 70 & $1 \mathrm{~b}$ \\
\hline $24^{a}$ & $\mathrm{~F}$ & $\mathrm{~T}$ & 31 & 22 & 9 & 40 & $1 a$ \\
\hline $25^{a}$ & F & $T$ & 33 & 8 & 25 & 90 & $1 a$ \\
\hline $26^{a}$ & $\mathrm{~F}$ & $T$ & 49 & 19 & 30 & 150 & NA \\
\hline $27^{\mathrm{b}}$ & $\mathrm{F}$ & $T$ & 22 & 10 & 12 & 20 & $1 a$ \\
\hline $28^{b}$ & M & $\mathrm{T}$ & 34 & 16 & 18 & 10 & $1 a$ \\
\hline $29^{b}$ & M & $\mathrm{T}$ & 33 & 18 & 15 & 50 & $1 \mathrm{a}$ \\
\hline $30^{b}$ & $\mathrm{~F}$ & $T$ & 56 & 52 & 4 & 60 & $2 a$ \\
\hline $31^{b}$ & $\mathrm{~F}$ & $\mathrm{~T}$ & 28 & 12 & 16 & 80 & $2 a$ \\
\hline $32^{b}$ & $\mathrm{~F}$ & Cer & 48 & No seizures & - & - & - \\
\hline $33^{b}$ & M & P & 16 & 11 & 5 & 60 & $1 b$ \\
\hline $34^{b}$ & $F$ & BS & 29 & No seizures & - & - & - \\
\hline
\end{tabular}

$M$ male, $F$ female, $F r$ frontal, $T$ temporal, $P$ parietal, Cer cerebellum, $B S$ brain stem ${ }^{a}$ FFPE (formalin-fixed, paraffin-embedded) tissue

${ }^{\mathrm{b}}$ Frozen tissue

cPeritumoral cortex tissue

${ }^{\mathrm{d}}$ Pre-operative seizure frequency

previously [26]. The probes were hybridized at $53{ }^{\circ} \mathrm{C}$ (miR21) and $56{ }^{\circ} \mathrm{C}$ (miR146a and miR155) for $1 \mathrm{~h}$, and the hybridization was detected with alkaline phosphatase (AP)labeled anti-DIG (Roche Applied Science, Basel, Switzerland) and AP-labeled anti-fluorescein (Roche Applied Science, Basel, Switzerland). NBT (nitro-blue tetrazolium chloride)/ BCIP (5-bromo-4-chloro-3'-indolyphosphate p-toluidine salt) was used as chromogenic substrate for AP. Negative control assays were performed without probes and without primary antibody (sections were blank). For the double-staining, combining immunocytochemistry with in situ hybridization, the sections were first processed for ISH and then processed for immunocytochemistry with glial fibrillary acidic protein (GFAP; monoclonal mouse, 
Sigma, St. Louis, Mo, USA; 1:4000), NeuN (neuronal nuclear protein; mouse clone MAB377; Chemicon, Temecula, CA, USA; 1:2000), (HLA)-DP, DQ, DR (mouse clone CR3/ 43; DAKO, Glostrup, Denmark; 1:400), or CD34 (mouse clone QBEnd10; Immunotech, Marseille, Cedex, France; 1:600). Signal was detected using the chromogen 3-amino9-ethylcarbazole (Sigma-Aldrich, St. Louis, MO, USA).

\section{RNA isolation}

For RNA isolation, frozen material or cell culture material was homogenized in Qiazol Lysis Reagent (Qiagen Benelux, Venlo, The Netherlands). The total RNA including the miRNA fraction was isolated using the miRNeasy Mini kit (Qiagen Benelux, Venlo, the Netherlands) according to manufacturer's instructions. The concentration and purity of RNA were determined at 260/280 nm using a Nanodrop spectrophotometer (Ocean Optics, Dunedin, FL, USA). Formalin-fixed paraffin-embedded (FFPE) material was processed for RNA isolation using QuickExtract $^{\text {tis }}$ FFPE (RNA Extraction Kit (Epicentre, Madison, WI, USA) according to manufacturer's instructions. The concentration of RNA was determined using Qubit $^{\circ} 2.0$ Fluorometer (Life Technologies, Carlsbad, CA, USA).

\section{Real-time quantitative PCR analysis (qPCR)}

miRNA (miR21, miR146a, miR155, and the U6B small nuclear RNA gene, Rnu6B; miR23a) expression was analyzed using Taqman microRNA assays (Applied Biosystems, Foster City, CA). cDNA was generated using Taqman MicroRNA reverse transcription kit (Applied Biosystems, Foster City, CA) according to the manufacturer's instructions, and the PCRs were run on a Roche Lightcycler 480 thermo cycler (Roche Applied Science, Basel, Switzerland).
Quantification of data was performed using the computer program LinRegPCR in which linear regression on the Log (fluorescence) per cycle number data is applied to determine the amplification efficiency per sample [36, 37]. The starting concentration of each specific product was divided by the starting concentration of reference gene (Rnu6B or miR23a), and this ratio was compared between groups.

To evaluate the microRNA targets (IRAK1, IRAK2, TNF receptor associated factor 6 (TRAF6), programmed cell death 4 (PDCD4), SHIP1, ERBB4, MEF2C, NOTCH1, NUMB, and phosphatase and tensin homolog (PTEN)), five micrograms of total RNA ( $n=10 \mathrm{GG} ; n=8$ controls) were reverse-transcribed into cDNA using oligo dT primers (see Additional file 1: Table S1).

\section{Immunohistochemistry}

Single-label immunohistochemistry (see Table 2) was performed, as previously described $[10,38]$. The sections were deparaffinated in xylene, rinsed in ethanol $(100 \%$, $95 \%, 70 \%$ ), and incubated for $20 \mathrm{~min}$ in $0.3 \%$ hydrogen peroxide diluted in methanol. Antigen retrieval was performed using a pressure cooker in $0.1 \mathrm{M}$ citrate buffer $\mathrm{pH} 6.0$ at $120{ }^{\circ} \mathrm{C}$ for $10 \mathrm{~min}$. Slides were washed with phosphate-buffered saline (PBS; 0.1 M, pH 7.4) and incubated overnight with the primary antibody in PBS at $4{ }^{\circ} \mathrm{C}$. Hereafter, the sections were washed in PBS and stained with a polymer-based peroxidase immunocytochemistry detection kit (PowerVision Peroxidase system, ImmunoVision, Brisbane, CA, USA). After washing, the sections were stained with $3,3^{\prime}$-diaminobenzidine tetrahydrochloride $(50 \mathrm{mg}$ DAB, Sigma-Aldrich, Zwijndrecht, The Netherlands) and $5 \mu \mathrm{l} 30 \%$ hydrogen peroxide in a $10-\mathrm{ml}$ solution of Tris- $\mathrm{HCl}$. The sections were counterstained with hematoxylin, dehydrated in alcohol and xylene, and

Table 2 Immunohistochemistry: primary antibodies

\begin{tabular}{llll}
\hline Antigen & Primary Antibody & Source & Dilution \\
\hline Glial fibrillary acidic protein (GFAP) & Polyclonal rabbit & DAKO, Glostrup, Denmark \\
Neuronal nuclear protein (NeuN) & Mouse clone MAB377 & Chemicon, Temecula, CA, USA \\
Synaptophysin & Mouse clone Sy38 & DAKO Glostrup, Denmark \\
Ki67 & Mouse clone MIB-1 & DAKO, Glostrup, Denmark \\
BRAF V600E & VE1 clone & $-{ }^{\text {a }}$ & \\
CD34 & Mouse clone QBEnd10 & Immunotech, Marseille, Cedex, France \\
Phospho-S6 ribosomal protein (pS6) & Monoclonal rabbit (Ser235/236) & Cell Signaling Technology, Beverly, MA, USA \\
Human leukocyte antigen (HLA-DP, DQ, DR; MHC-II) & Mouse clone CR3/43 & DAKO, Glostrup, Denmark \\
IL-13 & Polyclonal goat antibody & Santa Cruz Bio., CA, USA \\
IRAK1 & Mouse clone 3 F7 & Sigma, St. Louis, Mo, USA, \\
TRAF6 & Monoclonal rabbit & Abcam, Cambridge, MA, USA \\
PDCD4 & Polyclonal rabbit & Abcam, Cambridge, MA, USA \\
SHIP1 & Polyclonal rabbit & Cell Signaling, Beverly, MA, USA \\
\hline
\end{tabular}

MHC major histocompatibility complex

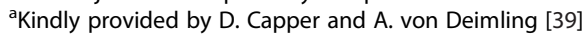


coverslipped. The sections incubated without primary antibodies or with pre-immune serum were essentially blank. The sections were counterstained with hematoxylin. Immunostaining for BRAF V600E (clone VE1, Spring Bioscience, Pleasanton, CA, USA; [39]) was performed on a Ventana BenchMark XT immunostainer (Ventana Medical Systems, Tucson, AZ, USA).

\section{Evaluation of histology and immunohistochemistry}

All labeled tissue sections were evaluated by two independent observers blinded to clinical data for the presence or absence of various histopathological parameters and specific immunoreactivity (IR) for the different markers. Hematoxylin-eosin (HE) stained slides were used to evaluate the neuronal and glial components of the tumors, the presence of dysplastic neurons, calcifications, and perivascular cuffs of lymphocytes. We also semiquantitatively evaluated the IR for the different markers, such as synaptophysin, GFAP, CD34, and HLA-DR (MHC-II). The intensity of IL-1 $\beta$ immunoreactive staining was evaluated using a scale of $0-3(0:-$, no; $1:+/-$, weak; $2:+$, moderate; $3:++$, strong staining). All areas of the tumors, as well the peritumoral cortex, were examined, and the score represents the predominant cell staining intensity found in each case. The frequency of IL-1 $\beta$, TRAF6, IRAK1, PDCD4, and SHIP1-positive cells [(1) rare, (2) sparse, (3) high] was also evaluated to give information about the relative number of positive glial cells within and around the tumor. As proposed before $[7,40]$, the product of these two values (intensity and frequency scores) was taken to give the overall score (total score; total score; immunoreactivity score; IRS). The numbers of HLA-DRpositive microglia/macrophages were quantified as previously described $[15,41]$.

\section{Cell cultures}

The astrocytoma cell line U373 was obtained from the American Type Culture Collection (Rockville, MD, USA); cells were cultured in Dulbecco's Modified Eagle's Medium (DMEM)/HAM F10 (1:1) supplemented with 50 units $/ \mathrm{ml}$ penicillin, $50 \mu \mathrm{g} / \mathrm{ml}$ streptomycin, and $10 \%$ FCS on poly-L-lysine-coated plates.

For astrocytes-enriched human cell cultures, fetal brain tissue (15-20 weeks of gestation) was obtained from spontaneous or medically induced abortions with appropriate maternal written consent for brain autopsy. Tissue was obtained in accordance with the Declaration of Helsinki and the AMC Research Code provided by the Medical Ethics Committee of the AMC. Resected tissue samples were collected in DMEM/HAM F10 (1:1) medium (Gibco, Life Technologies), supplemented with $50 \mathrm{units} / \mathrm{ml}$ penicillin and $50 \mu \mathrm{g} / \mathrm{ml}$ streptomycin and 10 $\%$ fetal calf serum (FCS). Cell isolation was performed as previously described [25].

\section{Treatment of cell cultures}

Human recombinant (r)IL-1 $\beta$ (Peprotech, NJ, USA; 10 $\mathrm{ng} / \mathrm{ml}$ ) was applied and maintained for $24 \mathrm{~h}$ before harvesting the cells for RNA isolation, as previously shown [42], the viability of human astrocytes in culture was not influenced by the treatments.

\section{Statistical analysis}

Statistical analyses were performed with SPSS for Windows (SPSS 20, SPSS Inc., Chicago, IL, USA). Continuous variables were described with mean and ranges; categorical variables with proportions and percentages. The two-tailed Student's $t$ test or the non-parametric Kruskal-Wallis test followed by the Dunn's post hoc test was used to assess differences between the groups. Correlation between immunohistochemical and clinical features (duration of epilepsy, seizure frequency, age at surgery, age at seizure onset, epilepsy outcome, etc.) were assessed using the Spearman's rank correlation test. A value of $p<0.05$ was defined as statistically significant.

\section{Results}

\section{Case material and histological features}

The clinical features of the cases included in this study are summarized in Table 1 . Among the 34 patients (15 males and 19 females) included in the study, 32 had a history of chronic pharmacoresistant epilepsy. Postoperatively, 30 out of 32 patients with epilepsy were completely seizure free (Engel's class I). Thirty-two had supratentorial tumors $(n=28$ in temporal lobe). The mean age at the time of surgery was 23.9 years (range $1-56$; SD 12.9). The mean age at epilepsy onset was 13.2 years (range 0.25-52; SD 9.5); the mean pre-operative seizure frequency was 67.6 per month (range 3-200; SD 45.9); and the mean duration of epilepsy was 10.5 years (range 0.5-31, SD 9). BRAF V600E mutation was evaluated in 33 GGs and detected in 15 cases (45.4 \%).

\section{miR21, miR146a, and miR155 expression by real-time qPCR in GG and peritumoral cortex}

miR21, miR146a, and miR155 expression was studied using qPCR in control human cerebral cortex samples and in GG samples. As previously shown for miR146a [25], there were no significant differences in expression between autopsy and surgical control samples, and miRNA expression levels between paired frozen and FFPE control samples were similar (not shown).

The expression of miR21, miR146a, and miR155 was evaluated in both the frozen (Fig. $1 ; n=9$ ) and FFPE (Fig. 2; $n=26)$ GG samples. Recent studies indicate a robust stability of miRNAs, supporting the accuracy of miRNA measurements with RT-qPCR also in FFPE tissues [43, 44].

Expression of miR21 in frozen tissues was significantly increased in GG compared to control cortex $(p=0.02$; 


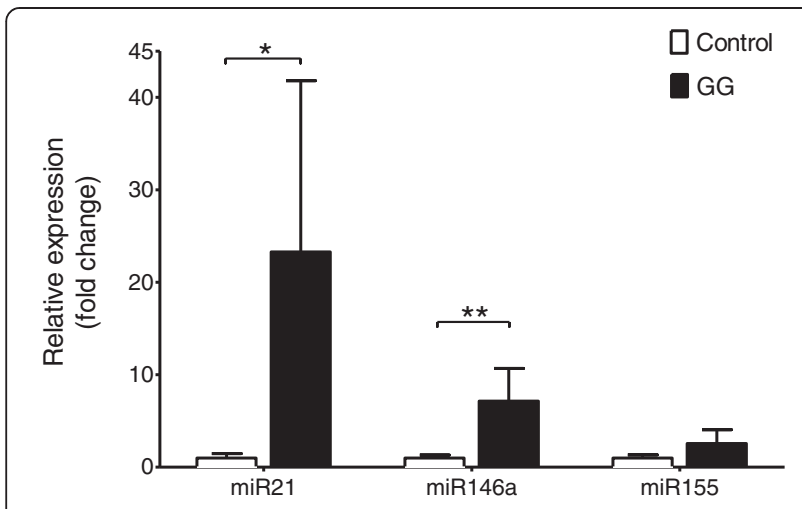

Fig. 1 Quantitative real-time PCR of miR21, miR146a, and miR155 in GG. Expression levels of miR21, miR146a, and miR155 in GG ( $n=9$; frozen material). Data are expressed relative to the levels observed in control cortex ( $n=8$, frozen material); miRNA expression was normalized to that of the U6B small nuclear RNA gene (Rnu6B). The error bars represent SEM; statistical significance: ${ }^{*} p<0.05$; ${ }^{* *} p<0.01$

Fig. 1). Evaluation of miR21 in a larger cohort (FFPE tissue; including 15 cases with perilesional cortex) showed a tendency towards increased expression compared to both control and peritumoral cortex ( $p=0.5$; Fig. 2).

Expression of miR146a in frozen tissue was significantly higher in GG compared to control cortex $(p=0.002$; Fig. 1). Increased expression of miR146a was observed in both the tumor and peritumoral cortex compared to the control samples (FFPE material; $p=0.01$; Fig. 2). There was no significant difference in the expression of miR146a between GG and peritumoral cortex.

Expression of miR155 in both frozen and FFPE tissue showed no difference between GG and control cortex
( $p=0.1$; Figs. 1 and 2). However, miR155 was highly expressed in peritumoral cortex, showing a significant difference compared to GG ( $p=0.01$; Fig. 2$)$.

miR21, miR146a, and miR155 cellular distribution by in situ hybridization in GG and peritumoral cortex

The cellular distribution of miR21, miR146a, and miR155 in GG and peritumoral cortex was investigated using in situ hybridization. In control cortex, miR146a was expressed at low levels in neuronal cells but was undetectable in glial cells (Fig. 3a). miR146a expression was increased in both tumor and peritumoral cortex. We detected miR146a expression in cells with typical astroglia morphology and in dysplastic neurons (Fig. 3b-d). Double labeling confirmed miR146a expression in NeuN- and GFAP-positive cells, whereas no detectable expression was observed in HLA-DR-positive cells of the microglial/ macrophage lineage (Fig. 3b-d); miR146a was also detected in BRAF V600E and IL-1 $\beta$-positive cells (Fig. 3d). miR146a was positively associated with miR155 expression within the tumor $(r=0.471, p=0.018$; Fig. 4a). The tumor miR146a expression was negatively correlated with the density of activated microglial cells $(r=-0.400$, $p=0.043$; Fig. 4b) and CD34 expression $(r=-0.541$, $p=0.037$; not endothelial cells). A positive correlation was observed between miR146a expression in the peritumoral cortex and GFAP IRS ( $r=0.695, p=0.004)$.

In both control and peritumoral cortex, miR21 was mainly detected in neuronal cells (Fig. 3e, f). In GG, the expression of miR21 was increased and it was detected in both neuronal and glial cells, as confirmed by doublelabeling experiments (Fig. 3g). A positive correlation was a

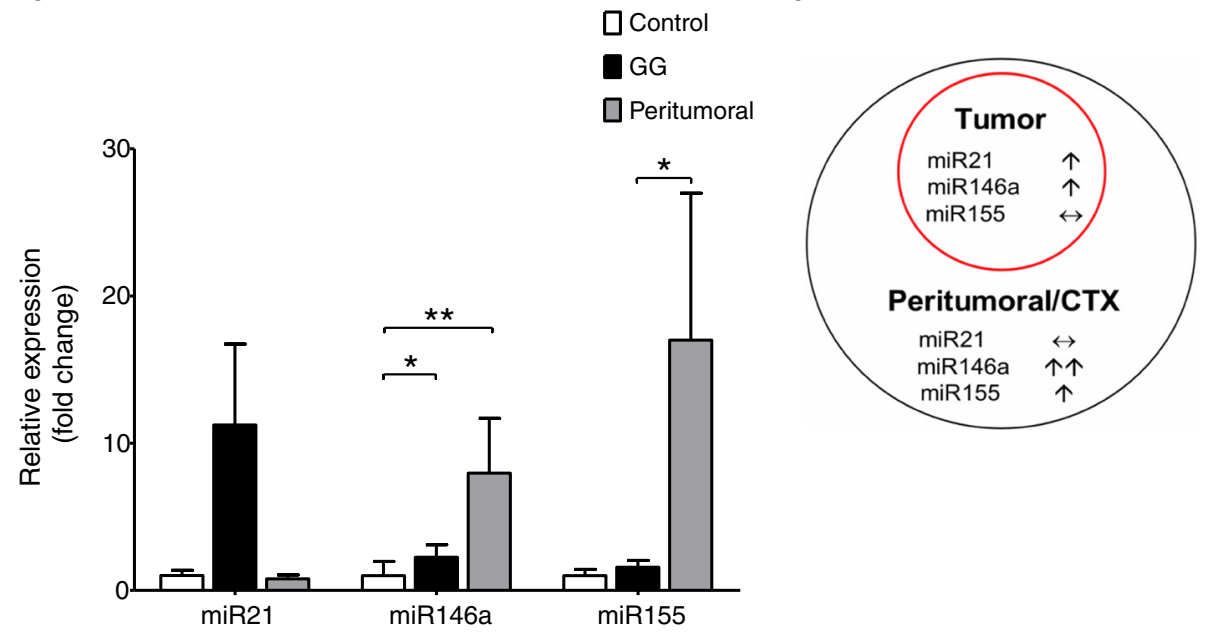

Fig. 2 miR21, miR146a, and miR155 expression levels in GG and peritumoral cortex. a Quantitative real-time PCR of miR21, miR146a, and miR155 in GG ( $n=26$; formalin-fixed, paraffin-embedded, FFPE material) and peritumoral cortex (ctx; $n=15 ;$ FFPE material). Data are expressed relative to the levels observed in control ctx ( $n=5$, FFPE); miRNAs expression was normalized to that of the U6B small nuclear RNA gene (Rnu6B). The error bars represent SEM; statistical significance: ${ }^{*} p<0.05$; ${ }^{* *} p<0.01$. b Schematic representation of miR21, miR146a, and miR155 changes in GG and peritumoral ctx 


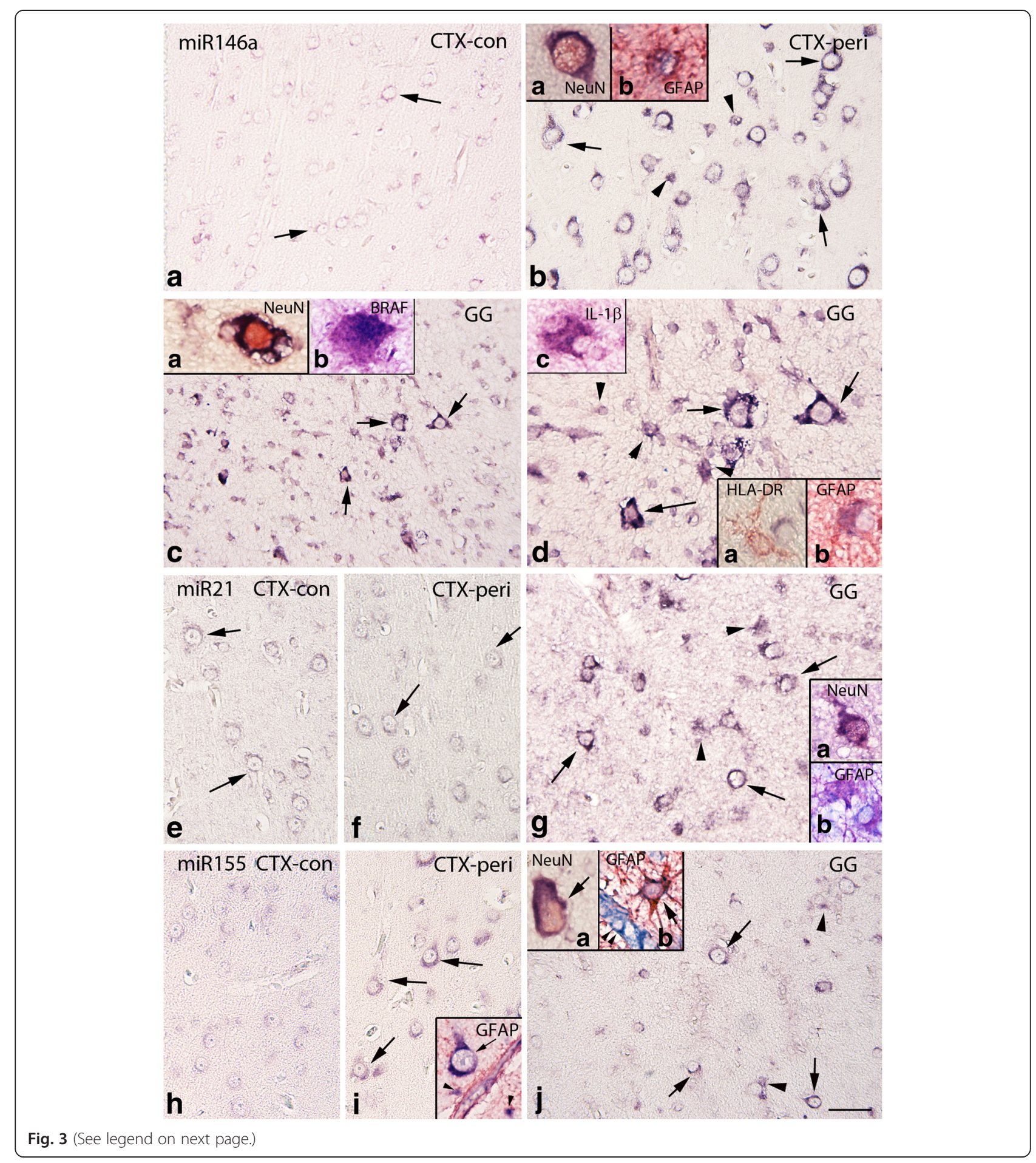


(See figure on previous page.)

Fig. 3 In situ hybridization of miR146a, miR21, and miR155 expression in control, peritumoral cortex, and GG. a-d miR146a. a Control cortex (-con); miR146a was expressed at low levels in neurons (arrows) and was undetectable in glial cells. b Peritumoral cortex (CTX-peri), showing miR146a expression in neurons (arrows) and glial cells (arrowheads). c-d GG; miR146a was expressed in both the neuronal (arrows) and the glial (arrowheads in d) tumor components. Inserts (a) in (b) and (c) show expression of miR146a in a neuron (NeuN positive, red); inserts (b) in (b) and in (d) show colocalization (purple) of miR146a with GFAP (red). Insert (b) in c shows colocalization (purple) of miR146a with BRAF (red). Insert (a) in (d) shows absence of colocalization with HLA-DR (microglia, red). Insert (c) in (d) shows colocalization (purple) of miR146a with IL-1 $\beta$ (red). e- $\mathbf{g}$ miR21. In both control (e) and peritumoral cortex (f), miR21 was expressed at low levels in neurons (arrows) and was undetectable in glial cells. $\mathbf{g}$ GG, showing miR21 expression in neurons (arrows) and glial cells (arrowheads). Insert (a) in (g) shows expression of miR21 in a neuron (NeuN positive, red); insert (b) shows expression of miR21 in astrocytes (GFAP positive, red). $\mathbf{h}-\mathbf{j}$ miR155. $\mathbf{h}$ Control cortex, showing low expression of miR155. In peritumoral cortex (i), moderate expression was observed in neurons (arrows). $\mathbf{j}$ GG, showing miR155 expression in neurons (arrows) and glial cells (arrowheads). Insert in i shows expression of miR155 in a neuron (arrow) and astrocytes (GFAP positive, red; arrowheads) around a positive blood vessel. Insert (a) in $\mathbf{j}$ shows expression of miR155 in a neuron (NeuN positive, red); insert (b) shows expression of miR155 in an astrocyte (GFAP positive, red; arrow) around a positive blood vessel (arrowheads); scale bar in (j): (a, c) $150 \mu \mathrm{m}$; (b, e-j) $80 \mu \mathrm{m}$; (d) $40 \mu \mathrm{m}$

observed between miR21 expression in GG and GFAP IRS $(r=0.396, p=0.045)$. Expression of miR155 in control cortex was mainly observed in neuronal cells (Fig. 3h). In peritumoral cortex and within the tumor, miR155 was expressed in both neurons and glial cells (NeuN- and GFAP-positive cells; Fig. 3i, j); we also observed expression of miR155 in blood vessels (peritumoral cortex and tumor; Fig. 3i, j).

\section{Regulation of miR21, miR146a, and miR155 expression by IL-1 $\beta$ in cell culture}

In the present study, we used both U373 glioblastoma cells and fetal astrocytes in culture to examine the effect of IL-1 $\beta$ on miR21, miR146a, and miR155 expression. qPCR analysis demonstrated that exposure to IL-1 $\beta$ increased miR21, miR146a, and miR155 expression in U373 cells (Fig. 5a). Also, a tendency towards increased extracellular miR21 levels was observed (Fig. 5b). In fetal astrocytes, we observed a prominent upregulation of both intracellular and extracellular miR146a (Fig. 5c, d).

miR21, miR146a, and miR155 expression and clinical features in GG

We found no statistically significant association between miR21, miR146a, and miR155 expression and clinical features, such as gender, age at surgery, location of the tumor, or duration of epilepsy. However, a negative correlation was observed between tumor and peritumoral miR146a expression and the pre-operative seizure frequency (GG: $r=-0.454, p=0.02$; Fig. 4c; peritumoral cortex: $r=-0.538, p=0.039)$.

\section{miRNA target expression in GG}

We evaluated the expression and cellular distribution of PDCD4 (target of miR21), TRAF6 and IRAK1 (target of miR146a), and SHIP1 (target of miR155) in GG by immunocytochemistry in the large cohort of samples (FFPE, $n=26$ ). Both PDCD4 and TRAF6 were expressed in the astroglial component of the tumor (Additional file 2: Figure S2A, B), and a negative correlation was observed between the PDCD4 IRS and the miR21 ( $r=-0.817, p=<0.001)$, as well as between the TRAF6 IRS and the miR146a $(r=-0.498, p=<0.05)$. Expression of TRAF6 was positively associated with the pre-operative seizure frequency $(r=0.651, p=<0.01)$, the density of activated microglial cells $(r=0.522, p=<0.01)$, and the IL-1 $\beta$ IRS $(r=0.515, p=<0.01)$. SHIP1 and IRAK1 were expressed in both neuronal and glial cells (Additional file 2: Figure S2C, D). There was a negative correlation between miR155 and SHIP1 protein expression
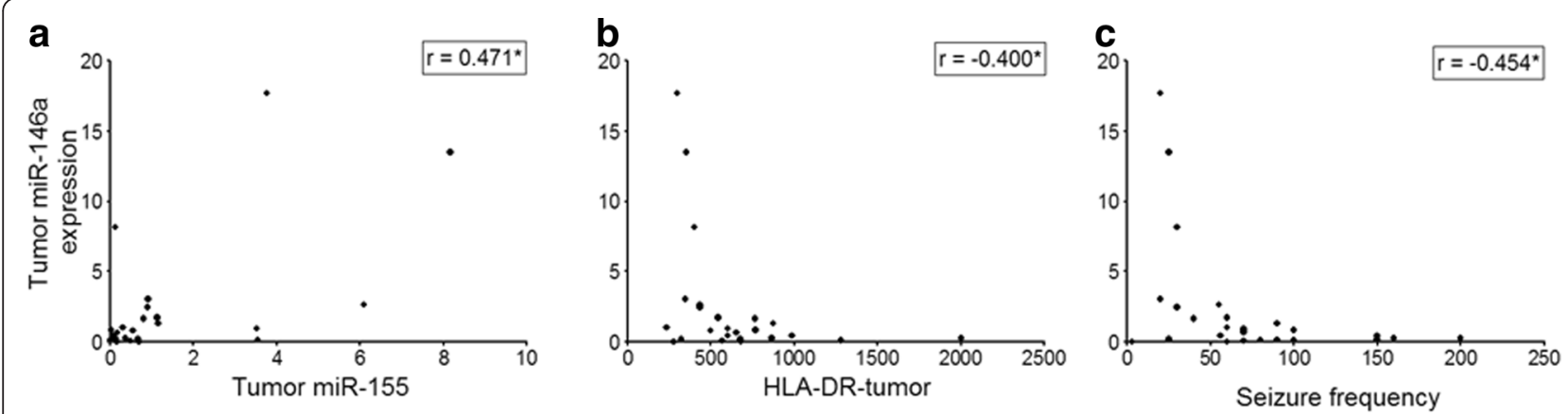

Fig. 4 miR146a expression in GG: correlation with miR155, number of HLA-DR-positive cells and seizure frequency. Scatter plots showing the significant correlation between tumor miR146a expression and (a) tumor miR155 expression; (b) number of HLA-DR-positive cells within the tumor; (c) pre-operative seizure frequency; $r=$ Spearman's rank correlation coefficient. ${ }^{*} p<0.05 ;{ }^{* *} p<0.01$ 
Intracelullar

a



C



Extracelullar

b



d

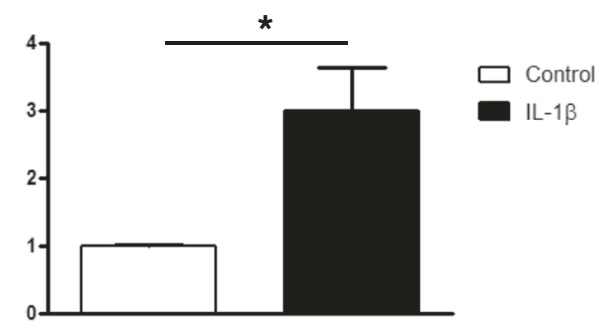

Fig. 5 miRNAs expression levels after exposure to IL-1 $\beta$ in culture. Quantitative real-time PCR. Cellular (a) and extracellular (b) levels of miR21, miR146a, and miR155 in U373 glioblastoma cells $24 \mathrm{~h}$ after exposure to IL-1 $\beta$ (10 ng/ml). Cellular (c) and extracellular (d) levels of miR146a in human fetal astrocytes in culture $24 \mathrm{~h}$ after exposure to $\mathrm{IL}-1 \beta(10 \mathrm{ng} / \mathrm{ml})$. Data are expressed relative to the levels observed in unstimulated cells and are mean \pm SEM from two cultures ( ${ }^{*} p<0.05$ compared to control). miRNAs expression was normalized to that of the U6B small nuclear RNA gene (Rnu6B) or to that of miR23a for the intra- and extracellular fractions, respectively

in glial cells in both tumor $(r=-0.439, p=<0.05)$ and in peritumoral cortex $(r=-0.699, p=<0.05)$. IRAK1 expression was negatively correlated with miR146a $(r=-0.560$, $p=<0.05)$. No significant correlations were observed between miR155 and neuronal SHIP1, as well as between miR146a and neuronal IRAK1.

Western blot analysis performed in a small cohort of GG $(n=8)$ showed an increased expression of TRAF6 compared to controls and variable expression of IRAK1 and IRAK2 (Additional file 3: Figure S3); only a tendency towards a negative correlation of miR146a with IRAK2 protein expression was observed $(r=-0.587, p=0.07)$.

Evaluation of mRNA expression levels of downstream targets of miR21 (PTEN, PDCD4, and MEF2C), miR146a (IRAK1, IRAK2 and TRAF6, ERBB4, NOTCH1, and NUMB), and miR155 (SHIP1) showed significant downregulation of PTEN and NUMB mRNA expression in GG compared to controls (data not shown; $p<0.001$ ). We also detected a negative correlation between PTEN mRNA and the miR21 $(r=-0.517, p=<0.04)$ and a tendency towards a negative correlation between NUMB mRNA and miR146a $(r=-0.497, p=0.0501)$.

\section{Microglial activation, IL-1 $\beta$, and clinical features in GG} The density of activated microglial cells (HLA-DR-positive cells) within the tumor was positively correlated with the pre-operative seizure frequency $(0.834, p<0.001)$, the duration of epilepsy (0.631, $p=0.001)$, and the age at surgery $(0.521, p=0.006)$; positive correlation was also observed with the IL-1 $\beta$ IRS in both tumor and peritumoral cortex (0.838, $p<0.001 ; 0.535, p=0.04$ ); Additional file 4: Figure S1A-C.

Expression of IL-1 $\beta$ in both tumor and peritumoral cortex was positively associated with the pre-operative seizure frequency (GG $0.855, p<0.001$; peritumoral ctx $0.579, p=0.02$ ) and the duration of epilepsy (GG 0.441, $p=0.02$; peritumoral ctx 0.669, $p=0.006$ ); Additional file 4: Figure S1D-F.

\section{Discussion}

GGs represent a major cause of medically intractable epilepsy in young patients; however, the cellular mechanisms underlying the intrinsic and high epileptogenicity of these lesions remain to be fully investigated $[1,2]$.

Over the past decade, an increasing number of experimental studies in animal models, as well as clinical and neuropathological observations, obtained in human brain specimens from various drug-resistant types of epilepsy (including GGs), demonstrated the relevance of inflammation in the pathophysiology of epilepsy (for reviews see $[11,14,45-47])$. In particular, the IL-1R/TLR proinflammatory pathway has been shown to critically contribute to seizure development, and targeting proinflammatory pathways has been suggested as strategy to obtain disease-modifying effects (i.e., decreased frequency and severity of chronic seizure and reduced 
comorbidity; $[46,48,49])$. Induction of both innate and adaptive immune system with prominent activation of proinflammatory proictogenic pathways (such as of the IL-1R/TLR) has also been observed in GGs ([7-9, 15, 50] present study). In this study, we provide additional evidence of the activation of the Toll-like and interleukin-1 receptor (TIRs) signaling, showing increased expression of downstream signaling molecules (IRAK1 and TRAF6) of the TIR pathway.

Interestingly, the density of activated microglial cells has been previously shown to be positively correlated with the frequency of seizures prior to surgical resection and the duration of epilepsy [15]. This observation has been confirmed in the present cohort, showing a positive correlation between the IL-1 $\beta$ expression and pre-operative seizure frequency, duration of epilepsy, as well as TRAF6 expression. A positive correlation was also observed between TRAF6 and the pre-operative seizure frequency, as well as the density of activated microglial cells.

Since several inflammatory pathways have been shown to be activated in concert in GGs [8], it is important to identify and evaluate upstream master regulators (such as miRNAs) of key proinflammatory/proictogenic pathways. In the present study, we investigated the expression and cellular distribution of miR21, miR146, and miR155, three miRNAs involved in the regulation of IL$1 R / T L R$ proinflammatory/proictogenic pathway in a large cohort of GGs. Our findings provide evidence of a differential regulation of these three miRNAs both within the tumor and in the peritumoral region, supporting their potential active role in the clinical behavior of the tumor. The cell-specific distribution of these miRNAs in relation with the epileptogenicity of the tumor is discussed below.

\section{miR21 expression and distribution in GG and peritumoral cortex}

Expression of miR21 has been observed in both tumor and peritumoral cortex with a tendency towards increased expression in the tumor compared to both control and peritumoral cortex. Recent studies indicate expression of this miRNA in both neuronal and glial cells [26, 51-53]. However, data about miR21 functions and cellular distribution in human brain are still limited. We observed neuronal expression in both control and peritumoral cortex, whereas within the tumor, miR21 expression was detected in both dysplastic neurons and tumor astrocytes.

miR21 has recently emerged as one of the important dysregulated miRNAs in many pathological conditions, including cardiovascular disease, brain injury, ischemia, and in a variety of human neoplastic disorders, representing the most commonly and strongly upregulated miRNA in high-grade gliomas $[54,55]$. Among the various targets of miR21 are tumor suppressors such as phosphatase and tensin homolog (PTEN), programmed cell death 4 (PDCD4), components of the p53 pathway, or transforming growth factor- $\beta$ (TGF- $\beta$ ) signaling, resulting in increase of cell proliferation, survival and migration/ invasion in tumors [54-56]. In our retrospective study, we could not determine whether the expression levels of this miRNA within the tumor would influence local recurrence on malignant transformation and evaluation of its role in the regulation of astrocytes proliferation and differentiation is still in progress. However, we observed a negative correlation between the expression of tumor PTEN mRNA, as well as of PDCD4 protein in tumor astrocytes and the level of tumor miR21, supporting the link between miR21 and these targets. The positive correlation observed between miR21 and the expression of tumor GFAP supports the role of astrocytes as targets of regulation and as a source of miR21.

Recently, miR21 has been shown to be upregulated in animal models of temporal lobe epilepsy (TLE) after induction of status epilepticus (SE) [26, 57]. In particular, we have shown a significant increase of this miRNA in three different hippocampal regions during the latent period preceding the onset of seizure [26] and associated with increased levels of proinflammatory cytokines, such as IL-1 [58]. miR21 can be induced by NF-kB and has been suggested to act as negative-feedback regulator of Toll-like receptor signaling via targeting of the proinflammatory tumor suppressor PDCD4 ([59]; for review see $[31,32,55,60])$. However, in our study, only modest increase was observed in glioma cells in response to IL$1 \beta$ and we did not find significant association between miR21 expression and clinical features, such as preoperative seizure frequency or duration of epilepsy.

In addition, miR21 (as well as miR155) has been recently shown to be upregulated in focal cortical dysplasia (FCD) tissue samples [61] and in cortical tubers of patients with tuberous sclerosis complex (TSC; van Scheppingen et al., unpublished observations), suggesting an epigenetic regulation of the mammalian target of rapamycin (mTOR) signaling pathway, which is also activated in GGs [10]. Thus, a potential role for this miRNA in neuronal dysfunction and mTOR activation can be considered and deserves further investigation.

\section{miR146a expression and distribution in GG and peritumoral cortex}

We confirmed, in a large tumor cohort, the previously observed increased expression of miR146a in GG [25]. In situ hybridization showed increased expression of this miRNA in tumor astrocytes and colocalization with IL$1 \beta$ was observed. Accordingly, IL- $1 \beta$ represents a major inducer of this miRNA in both human astrocytes and glioma cells ([25]; present data). Similar to miR21, miR146a has also been shown to increase in reactive 
astrocytes at 1 week after $\mathrm{SE}$, which corresponds to the time of maximal astroglial activation $[26,62]$ and upregulation in astrocytes has also been reported in human TLE $[62,63]$. Recent studies support the function of this miRNA as a key negative-feedback regulator of the astrocyte-mediated inflammatory response (for reviews see [31, 32]). In particular, miR146a overexpression has been shown to reduce major inflammatory molecules induced by IL-1 $\beta$ [25]. Accordingly, we observed a negative correlation between the level of tumor miR146a and the expression of TRAF6, a downstream signaling molecule of the TIR signaling pathway that has previously been shown to be a miR146 target. Interestingly, the expression of TRAF6 was positively associated with the pre-operative seizure frequency.

In our cohort, the tumor miR146a expression was negatively correlated with the density of activated microglial cells. Moreover, we also observed a negative correlation between tumor miR146a expression and the pre-operative seizure frequency. Interestingly, alterations of miR146a brain level have recently shown to modify acute seizures in mice and to affect brain inflammation triggered by activation of the proictogenic IL-1R/TLR signaling pathway ([64]; unpublished observation), supporting the potential for targeting this miRNA as strategy for modulating inflammatory pathways and seizure activity.

Secreted miRNAs may represent a new form of intercellular communication, acting as signaling molecules [65-67] and have been also shown to play a key role in the biology of the tumor microenvironment [68]. In the present study, we provide evidence of release of miR146a upon stimulation with IL-1 $\beta$ in fetal human astrocytes in culture.

Surprisingly, miR146a is also expressed within the dysplastic and immature neuronal cell components of GG, and we observed a negative correlation between the levels of this miRNA and the expression of the precursor cell marker, CD34 [69]. Interestingly, miR146a has been recently shown to modulate neural stem cell proliferation and differentiation, and induction of this miRNA in gliomas has been suggested to represent a negativefeedback mechanism to restrict tumor growth [70]. Such inhibitory function of miR146a on gliomas has been attributed to the down-regulation of the key neural stem cell factor NOTCH1 [70]. However, another key target of mir146a is represented by NUMB [71, 72] that has been shown to regulate cell fate and growth, acting as tumor suppressor [73-75]. Interestingly, we observed a down-regulation of NUMB in GG and a tendency towards a negative correlation with miR146a. Thus, further study is required to determine whether the expression levels of this miRNA would differentially regulate proliferation and/or differentiation of GG glial and neuronal components. Moreover, since a mutation of the BRAF oncogene is frequently observed in GGs [39, 50, 76, 77], its relationship with the expression of miR146a represents another aspect that deserves attention. Accordingly, a recent study shows that miR146a, upregulated by oncogenic BRAF, promotes the initiation and progression of melanoma cells through down-regulation of NUMB [78]. In our study, we observed a colocalization with the BRAF V600E-mutated protein in dysplastic neurons.

Increased expression of miR146a has been also observed in the peritumoral cortex with expression in reactive astrocytes, and a positive correlation was observed between miR146a levels and the expression of GFAP. Both clinical and experimental studies support the epileptogenicity of the peritumoral zone, which may contribute to the generation and propagation of seizure activity [79-81]. The negative correlation observed between peritumoral miR146a expression and the pre-operative seizure frequency support the potential contribution of this miRNA to the peritumoral epileptogenic network.

\section{miR155 expression and distribution in GG and peritumoral cortex}

miR155 has been extensively studied as a cancer-associated miRNA and has been shown to be over-expressed in various types of cancers (for review see $[30,56]$ ). In particular, it has been recently shown to promote glioma cell proliferation via the regulation of MXI1 [82] and GABA receptors [83]. In our study, miR155 has been observed in both tumor and peritumoral cortex, with increased expression in peritumoral tissue compared to the tumor. In both tumor and peritumoral cortex, we observed astroglial expression of miR155. Accordingly, this miRNA has been shown to be expressed in human astrocytes and upregulated in response to cytokines and TLR ligands [84]. Increased expression of this miRNA has been also reported in multiple sclerosis lesions [85]. In our study, we showed induction of miR155 in response to IL-1 $\beta$ in glioma cells. Although miR155 has been shown to exert both positive and negative effects on the NF-kB signaling proteins ([86]; reviewed in $[30,31])$, in vitro studies support the positive role in the induction of proinflammatory genes in human astrocytes [84]. Thus, the expression of this miRNA observed in the peritumoral area may counteract the antiinflammatory function of miR146. miR21 has been shown to play an important role in the regulation of miR155 expression by promoting the expression of IL-10, a key negative regulator of miR155 expression [30, 31]. Interestingly, low levels of expression were detected for miR21 in the peritumoral cortex.

In both tumor and peritumoral cortex, expression of miR155 has been also detected in endothelial cells. Accordingly, miR155 has been shown to regulate endothelial cell functions and angiogenesis and negatively affect bloodbrain barrier function during neuroinflammation [87-90]. 
Recently, miR155 has been shown be upregulated in animal models of TLE [91, 92], as well as in FCD tissue samples [61] and in TSC (van Scheppingen et al., unpublished observations). In the present study, we did not find a significant association between miR155 expression and clinical features, such as pre-operative seizure frequency or duration of epilepsy.

An issue to be considered in the interpretation of these data is represented by the possible influence of anti-epileptic drugs, such as valproate and phenobarbital, on miRNAs expression [93, 94].

In conclusion, this study provides information on the cellular distribution and expression of three inflammationrelated microRNAs in GGs. Our results indicate a differential regulation of these miRNA involving also the epileptogenic peritumoral region. In particular, the negative correlation observed between miR146a expression, the density of activated microglial cells, and the preoperative seizure frequency support the potential role of miR146a in regulating the clinical behavior of these epileptogenic lesions, pointing to this upstream regulator of proinflammatory/proictogenic pathways as attractive target for further preclinical studies in drug-resistant epilepsies.

\section{Additional files}

Below is the link to the electronic supplementary material.

\section{Additional file 1: Table S1. Real-time quantitative PCR analysis ( $q P C R$;} microRNA targets).

Additional file 2: Figure S2. PDCD4, TRAF6, SHIP1, and IRAK1 expression in GG. Representative photomicrographs of PDCD4 (A), TRAF6 (B), SHIP1, (C) and IRAK1 (D) IR in GG showing expression in tumor astrocytes (arrows); arrowhead in C shows neuronal expression of SHIP1 (C); insert in D: IRAK1 positive neuron (D). Sections were counterstained with hematoxylin. A-F: scale bar: $40 \mu \mathrm{m}$.

Additional file 3: Figure S3. TRAF6, IRAK1, and IRAK2 protein expression. Western blot analysis. A-C: representative immunoblot of total homogenates from GG densitometric analysis: values (optical density units, O.D.) are mean \pm SEM $(n=8)$, relative to the optical density of $\beta$-actin; ${ }^{*} p<0.05$, compared to controls $(n=6)$. (PPTX $72 \mathrm{~kb})$

Additional file 4: Figure S1. HLA-DR-positive cells and $I L-1 \beta$ expression in GG: correlation with clinical variables. A-C: scatter plots showing the significant correlation between HLA-DR-positive cells and (A) tumor IL-1 $\beta$ immunoreactivity score (IRS; insert in A shows IL-1 $\beta$ IR within the tumor); (B) pre-operative seizure frequency and (C) duration of epilepsy. D-F: Scatter plots showing the significant correlation between tumor and (D) peritumoral IL-1 $\beta$ IRS (insert in D shows IL-positive astrocytes within the peritumoral cortex); (E) pre-operative seizure frequency and (F) duration of epilepsy; $r=$ Spearman's rank correlation coefficient, ${ }^{*} p<0.05,{ }^{* *} p<0.01$.

\section{Competing interests}

The authors declare that they have no competing interests.

\section{Authors' contributions}

ASP carried out the $\mathrm{PPCR}$, in situ hybridization, and immunohistochemistry and western blot together with AMI. JvS and AMI performed the experiments in cell cultures. JJA contributed to the preparation of tissue samples and immunohistochemistry. WGMS, PCVR, AYNS, and EA contributed to the collection of clinical data and selection of tissue samples. The overall experimental design was conceived and supervised by EA.AMI, JvS, AYNS, and EA helped AP in drafting and preparing the manuscript for submission. All authors read and approved the final manuscript.

\section{Acknowledgements}

This work was supported by the National Epilepsy Fund-"Power of the Small", the Hersenstichting Nederland (NEF 012-12; NF-13-1) and KIKA (Stichting Kinderen Kankervrij; AP, EA, AYNS). We confirm that we have read the journal's position on issues involved in ethical publication and affirm that this report is consistent with those guidelines.

\section{Author details}

'Department of (Neuro)Pathology, Academic Medical Center, University of Amsterdam, Meibergdreef 9, 1105 AZ Amsterdam, The Netherlands. ${ }^{2}$ Department of Pediatric Oncology, Emma Children's Hospital, Academic Medical Center, University of Amsterdam, Meibergdreef 9, 1105 AZ Amsterdam, The Netherlands. ${ }^{3}$ Department of Pathology, Rudolf Magnus Institute for Neuroscience, University Medical Center Utrecht, Utrecht, The Netherlands. ${ }^{4}$ Department of Neurosurgery, Rudolf Magnus Institute for Neuroscience, University Medical Center Utrecht, Utrecht, The Netherlands. ${ }^{5}$ SEIN - Stichting Epilepsie Instellingen Nederland, Heemstede, The Netherlands. ${ }^{6}$ Swammerdam Institute for Life Sciences, Center for Neuroscience, University of Amsterdam, Amsterdam, The Netherlands.

Received: 8 December 2014 Accepted: 30 April 2015

Published online: 20 May 2015

\section{References}

1. Blumcke I, Aronica E, Urbach H, Alexopoulos A, Gonzalez-Martinez JA. A neuropathology-based approach to epilepsy surgery in brain tumors and proposal for a new terminology use for long-term epilepsy-associated brain tumors. Acta Neuropathol. 2014;128:39-54

2. Thom M, Blumcke I, Aronica E. Long-term epilepsy-associated tumors. Brain Pathol. 2012:22:350-79.

3. Blumcke I, Wiestler OD. Gangliogliomas: an intriguing tumor entity associated with focal epilepsies. J Neuropathol Exp Neurol. 2002;61:575-84.

4. Majores M, von Lehe M, Fassunke J, Schramm J, Becker AJ, Simon M. Tumor recurrence and malignant progression of gangliogliomas. Cancer. 2008;113:3355-63.

5. Giulioni M, Gardella E, Rubboli G, Roncaroli F, Zucchelli M, Bernardi B, et al. Lesionectomy in epileptogenic gangliogliomas: seizure outcome and surgical results. J Clin Neurosci. 2006;13:529-35.

6. Englot DJ, Berger MS, Barbaro NM, Chang EF. Factors associated with seizure freedom in the surgical resection of glioneuronal tumors. Epilepsia. 2012:53:51-7.

7. Ravizza T, Boer K, Redeker S, Spliet WG, van Rijen PC, Troost D, et al. The IL-1beta system in epilepsy-associated malformations of cortical development. Neurobiol Dis. 2006;24:128-43.

8. Aronica E, Boer K, Becker A, Redeker S, Spliet WG, van Rijen PC, et al. Gene expression profile analysis of epilepsy-associated gangliogliomas. Neuroscience. 2008;151:272-92.

9. Prabowo AS, lyer AM, Anink JJ, Spliet WG, van Rijen PC, Aronica E. Differential expression of major histocompatibility complex class I in developmental glioneuronal lesions. J Neuroinflammation. 2013;10:12.

10. Prabowo AS, lyer AM, Veersema TJ, Anink JJ, Schouten-van Meeteren AY, Spliet WG, et al. BRAF V600E mutation is associated with mTOR signaling activation in glioneuronal tumors. Brain Pathol. 2014;24:52-66.

11. Aronica E, Crino PB. Inflammation in epilepsy: clinical observations. Epilepsia. 2011;52 Suppl 3:26-32.

12. Vezzani A, French J, Bartfai T, Baram TZ. The role of inflammation in epilepsy. Nat Rev Neurol. 2011;7:31-40.

13. Vezzani A, Auvin S, Ravizza T, Aronica E. Glia-neuronal interactions in ictogenesis and epileptogenesis: role of inflammatory mediators. In: Noebels JL, Avoli M, Rogawski MA, Olsen RW, Delgado-Escueta AV, editors. Jasper's basic mechanisms of the epilepsies. 4th ed. Bethesda: National Center for Biotechnology Information (US); 2012.

14. Aronica E, Ravizza T, Zurolo E, Vezzani A. Astrocyte immune responses in epilepsy. Glia. 2012;60:1258-68.

15. Aronica E, Gorter JA, Redeker S, Ramkema M, Spliet WG, van Rijen PC, et al. Distribution, characterization and clinical significance of microglia in glioneuronal tumours from patients with chronic intractable epilepsy. Neuropathol Appl Neurobiol. 2005;31:280-91. 
16. Boer K, Spliet WG, van Rijen PC, Redeker S, Troost D, Aronica E. Evidence of activated microglia in focal cortical dysplasia. J Neuroimmunol. 2006;173:188-95.

17. Sethi P, Lukiw WJ. Micro-RNA abundance and stability in human brain: specific alterations in Alzheimer's disease temporal lobe neocortex. Neurosci Lett. 2009:459:100-4.

18. Li L, Chen XP, Li YJ. MicroRNA-146a and human disease. Scand J Immunol. 2010;71:227-31.

19. Ha TY. MicroRNAs in human diseases: from cancer to cardiovascular disease. Immune Netw. 2011;11:135-54.

20. Rao P, Benito E, Fischer A. MicroRNAs as biomarkers for CNS disease. Front Mol Neurosci. 2013;6:39.

21. Henshall DC. MicroRNAs in the pathophysiology and treatment of status epilepticus. Front Mol Neurosci. 2013;6:37.

22. Li MM, Li XM, Zheng XP, Yu JT, Tan L. MicroRNAs dysregulation in epilepsy Brain Res. 2014;1584:94-104.

23. Kretschmann A, Danis B, Andonovic L, Abnaof K, van Rikxoort M, Siegel F, et al. Different microRNA profiles in chronic epilepsy versus acute seizure mouse models. J Mol Neurosci. 2015;55(2):466-79.

24. Kan AA, van Erp S, Derijck AA, de Wit M, Hessel EV, O'Duibhir E, et al. Genome-wide microRNA profiling of human temporal lobe epilepsy identifies modulators of the immune response. Cell Mol Life Sci. 2012;69:3127-45.

25. Iyer A, Zurolo E, Prabowo A, Fluiter K, Spliet WG, van Rijen PC, et al. MicroRNA-146a: a key regulator of astrocyte-mediated inflammatory response. PLOS ONE. 2012;7, e44789.

26. Gorter JA, Iyer A, White I, Colzi A, van Vliet EA, Sisodiya S, et al. Hippocampal subregion-specific microRNA expression during epileptogenesis in experimental temporal lobe epilepsy. Neurobiol Dis. 2014;62:508-20.

27. Taganov KD, Boldin MP, Chang KJ, Baltimore D. NF-kappaB-dependent induction of microRNA miR-146, an inhibitor targeted to signaling proteins of innate immune responses. Proc Natl Acad Sci U S A. 2006;103:12481-6.

28. Sheedy FJ, O'Neill LA. Adding fuel to fire: microRNAs as a new class of mediators of inflammation. Ann Rheum Dis. 2008;67 Suppl 3:iii50-5.

29. Cui JG, Li YY, Zhao Y, Bhattacharjee S, Lukiw WJ. Differential regulation of interleukin-1 receptor-associated kinase-1 (IRAK-1) and IRAK-2 by microRNA-146a and NF-kappaB in stressed human astroglial cells and in Alzheimer disease. J Biol Chem. 2010;285:38951-60

30. Quinn SR, O'Neill LA. A trio of microRNAs that control Toll-like receptor signalling. Int Immunol. 2011:23:421-5.

31. O'Neill LA, Sheedy FJ, McCoy CE. MicroRNAs: the fine-tuners of Toll-like receptor signalling. Nat Rev Immunol. 2011;11:163-75.

32. He X, Jing Z, Cheng G. MicroRNAs: new regulators of Toll-like receptor signalling pathways. Biomed Res Int. 2014:2014:945169.

33. Louis DN, Ohgaki H, Wiestler OD, Cavanee WK. WHO classification of tumours of the central nervous system. Lyon: IARC; 2007.

34. van Veelen CW, Debets RM, van Huffelen AC, van Emde BW, Binnie CD, Storm van Leeuwen W, et al. Combined use of subdural and intracerebral electrodes in preoperative evaluation of epilepsy. Neurosurgery. 1990;26:93-101.

35. Engel JJ. Outcome with respect to epileptic seizures. In: Engel JJ, editor. Surgical treatment of the epilepsies. New York: Raven; 1993. p. 609-21.

36. Ramakers C, Ruijter JM, Deprez RH, Moorman AF. Assumption-free analysis of quantitative real-time polymerase chain reaction (PCR) data. Neurosci Lett. 2003;339:62-6.

37. Ruijter JM, Ramakers C, Hoogaars WM, Karlen Y, Bakker O, van den Hoff MJ, et al. Amplification efficiency: linking baseline and bias in the analysis of quantitative PCR data. Nucleic Acids Res. 2009:37, e45.

38. Aronica E, Gorter JA, Jansen GH, van Veelen CW, van Rijen PC, Ramkema M, et al. Expression and cell distribution of group I and group II metabotropic glutamate receptor subtypes in Taylor-type focal cortical dysplasia. Epilepsia. 2003;44:785-95.

39. Capper D, Preusser M, Habel A, Sahm F, Ackermann U, Schindler G, et al. Assessment of BRAF V600E mutation status by immunohistochemistry with a mutation-specific monoclonal antibody. Acta Neuropathol. 2011;122:11-9.

40. Aronica E, Boer K, van Vliet EA, Baayen JC, Redeker S, Spliet WGM, et al. Complement activation in experimental and human temporal lobe epilepsy. Neurobiol Dis. 2007;26:497-511

41. Maldonado M, Baybis M, Newman D, Kolson DL, Chen W, McKhann 2nd G, et al. Expression of ICAM-1, TNF-alpha, NF kappa B, and MAP kinase in tubers of the tuberous sclerosis complex. Neurobiol Dis. 2003;14:279-90.

42. Aronica E, Gorter JA, Rozemuller AJ, Yankaya B, Troost D. Interleukin-1 beta down-regulates the expression of metabotropic glutamate receptor 5 in cultured human astrocytes. J Neuroimmunol. 2005;160:188-94.
43. de Biase D, Visani M, Morandi L, Marucci G, Taccioli C, Cerasoli S, et al. miRNAs expression analysis in paired fresh/frozen and dissected formalin fixed and paraffin embedded glioblastoma using real-time pCR. PLoS ONE. 2012;7:e35596

44. Scott A, Ambannavar R, Jeong J, Liu ML, Cronin MT. RT-PCR-based gene expression profiling for cancer biomarker discovery from fixed, paraffin-embedded tissues. Methods Mol Biol. 2011;724:239-57.

45. Vezzani A, Aronica E, Mazarati A, Pittman QJ. Epilepsy and brain inflammation. Exp Neurol. 2011;244:11-21.

46. Vezzani A, Bartfai T, Bianchi M, Rossetti C, French J. Therapeutic potential of new antiinflammatory drugs. Epilepsia. 2011;52 Suppl 8:67-9.

47. Aronica E, Crino PB. Epilepsy related to developmental tumors and malformations of cortical development. Neurotherapeutics. 2014;11:251-68.

48. Maroso M, Balosso S, Ravizza T, Liu J, Aronica E, lyer AM, et al. Toll-like receptor 4 and high-mobility group box-1 are involved in ictogenesis and can be targeted to reduce seizures. Nat Med. 2010;16:413-9.

49. Iori V, Maroso M, Rizzi M, Iyer AM, Vertemara R, Carli M, et al. Receptor for advanced glycation endproducts is upregulated in temporal lobe epilepsy and contributes to experimental seizures. Neurobiol Dis. 2013:58C:102-14.

50. Prabowo AS, lyer AM, Veersema TJ, Anink JJ, Schouten-van Meeteren AYN, Spliet WGM, et al. BRAF V600E mutation is associated with mTOR signalling activation in glioneuronal tumors. Brain Pathol. 2014;24(1):52-66.

51. Buller B, Liu X, Wang X, Zhang RL, Zhang L, Hozeska-Solgot A, et al. MicroRNA-21 protects neurons from ischemic death. FEBS J. 2010;277:4299-307.

52. Bhalala OG, Pan L, Sahni V, McGuire TL, Gruner K, Tourtellotte WG, et al. MicroRNA-21 regulates astrocytic response following spinal cord injury. J Neurosci. 2012;32:17935-47.

53. Zhang L, Dong LY, Li YJ, Hong Z, Wei WS. miR-21 represses FasL in microglia and protects against microglia-mediated neuronal cell death following hypoxia/ ischemia. Glia. 2012;60:1888-95.

54. Krichevsky AM, Gabriely G. miR-21: a small multi-faceted RNA. J Cell Mol Med. 2009:13:39-53.

55. Kumarswamy R, Volkmann I, Thum T. Regulation and function of miRNA-21 in health and disease. RNA Biol. 2011:8:706-13.

56. Tili E, Michaille JJ, Croce CM. MicroRNAs play a central role in molecular dysfunctions linking inflammation with cancer. Immunol Rev. 2013;253:167-84

57. Risbud RM, Lee C, Porter BE. Neurotrophin-3 mRNA a putative target of miR21 following status epilepticus. Brain Res. 2011;1424:53-9.

58. Gorter JA, Van Vliet E, Aronica E, Rauwerda H, Breit T, da Silva FHL, et al. Potential new antiepileptogenic targets indicated by microarray analysis in a rat model for temporal lobe epilepsy. J Neurosci. 2006;26:11083-110.

59. Sheedy FJ, Palsson-McDermott E, Hennessy EJ, Martin C, O'Leary JJ, Ruan Q, et al. Negative regulation of TLR4 via targeting of the proinflammatory tumor suppressor PDCD4 by the microRNA miR-21. Nat Immunol. 2010;11:141-7.

60. O'Connell RM, Rao DS, Baltimore D. MicroRNA regulation of inflammatory responses. Annu Rev Immunol. 2012;30:295-312.

61. Lee JY, Park AK, Lee ES, Park WY, Park SH, Choi JW, et al. miRNA expression analysis in cortical dysplasia: regulation of MTOR and LIS1 pathway. Epilepsy Res. 2014;108:433-41

62. Aronica E, Fluiter K, lyer A, Zurolo E, Vreijling J, van Vliet EA, et al. Expression pattern of miR-146a, an inflammation-associated microRNA, in experimental and human temporal lobe epilepsy. Eur J Neurosci. 2010;31:1100-7.

63. Omran A, Peng J, Zhang C, Xiang QL, Xue J, Gan N, et al. Interleukin-1beta and microRNA-146a in an immature rat model and children with mesial temporal lobe epilepsy. Epilepsia. 2012;53:1215-24.

64. Iori V, lyer A, Aronica E, Vezzani A. Epigenetic control of brain inflammation in epilepsy: new therapeutic opportunity by targeting miR146a. Abstract In Proceedings of American Epilepsy Society conference, Philadelphia. Epilepsy Curr. 2014:15(s1):364

65. Lehmann SM, Kruger C, Park B, Derkow K, Rosenberger K, Baumgart J, et al. An unconventional role for miRNA: let-7 activates Toll-like receptor 7 and causes neurodegeneration. Nat Neurosci. 2012;15:827-35.

66. Zhang Q, Xu J, Chen Q, Chen X, Zen K, Zhang CY. Selective secretion of microRNA in CNS system. Protein Cell. 2013;4:243-7.

67. Jin XF, Wu N, Wang L, Li J. Circulating microRNAs: a novel class of potentia biomarkers for diagnosing and prognosing central nervous system diseases. Cel Mol Neurobiol. 2013;33:601-13.

68. Challagundla KB, Fanini F, Vannini I, Wise P, Murtadha M, Malinconico L, et al. MicroRNAs in the tumor microenvironment: solving the riddle for a better diagnostics. Expert Rev Mol Diagn. 2014;14:565-74. 
69. Blumcke I, Giencke K, Wardelmann E, Beyenburg S, Kral T, Sarioglu N, et al. The CD34 epitope is expressed in neoplastic and malformative lesions associated with chronic, focal epilepsies. Acta Neuropathol. 1999;97:481-90.

70. Mei J, Bachoo R, Zhang CL. MicroRNA-146a inhibits glioma development by targeting Notch1. Mol Cell Biol. 2011;31:3584-92.

71. Hung PS, Liu CJ, Chou CS, Kao SY, Yang CC, Chang KW, et al. miR-146a enhances the oncogenicity of oral carcinoma by concomitant targeting of the IRAK1, TRAF6 and NUMB genes. PLoS ONE. 2013;8:e79926.

72. Hwang WL, Jiang JK, Yang SH, Huang TS, Lan HY, Teng HW, et al. MicroRNA-146a directs the symmetric division of Snail-dominant colorectal cancer stem cells. Nat Cell Biol. 2014;16:268-80.

73. Gulino A, Di Marcotullio L, Screpanti I. The multiple functions of Numb. Exp Cell Res. 2010;316:900-6.

74. Di Marcotullio L, Greco A, Mazza D, Canettieri G, Pietrosanti L, Infante P, et al. Numb activates the E3 ligase Itch to control Gli1 function through a novel degradation signal. Oncogene. 2011;30:65-76.

75. Jiang $X$, Xing H, Kim TM, Jung Y, Huang W, Yang HW, et al. Numb regulates glioma stem cell fate and growth by altering epidermal growth factor receptor and Skp1-Cullin-F-box ubiquitin ligase activity. Stem Cells. 2012;30:1313-26.

76. Schindler G, Capper D, Meyer J, Janzarik W, Omran H, Herold-Mende C, et al. Analysis of BRAF V600E mutation in 1,320 nervous system tumors reveals high mutation frequencies in pleomorphic xanthoastrocytoma, ganglioglioma and extra-cerebellar pilocytic astrocytoma. Acta Neuropathol. 2011;121:397-405.

77. Dahiya S, Haydon DH, Alvarado D, Gurnett CA, Gutmann DH, Leonard JR BRAF(V600E) mutation is a negative prognosticator in pediatric ganglioglioma. Acta Neuropathol. 2013;125:901-10.

78. Forloni M, Dogra SK, Dong Y, Conte Jr D, Ou J, Zhu LJ, et al. miR-146a promotes the initiation and progression of melanoma by activating Notch signaling. Elife. 2014;3:e01460.

79. van Breemen MS, Wilms EB, Vecht CJ. Epilepsy in patients with brain tumours: epidemiology, mechanisms, and management. Lancet Neurol. 2007;6:421-30.

80. Rajneesh KF, Binder DK. Tumor-associated epilepsy. Neurosurg Focus. 2009;27, E4.

81. de Groot M, Reijneveld JC, Aronica E, Heimans JJ. Epilepsy in patients with a brain tumour: focal epilepsy requires focused treatment. Brain. 2012;135:1002-16.

82. Zhou J, Wang W, Gao Z, Peng X, Chen X, Chen W, et al. MicroRNA-155 promotes glioma cell proliferation via the regulation of MXI1. PLOS ONE. 2013;8, e83055.

83. D'Urso PI, D'Urso OF, Storelli C, Mallardo M, Gianfreda CD, Montinaro A, et al. miR-155 is up-regulated in primary and secondary glioblastoma and promotes tumour growth by inhibiting GABA receptors. Int J Oncol. 2012;41:228-34

84. Tarassishin L, Loudig O, Bauman A, Shafit-Zagardo B, Suh HS, Lee SC. Interferon regulatory factor 3 inhibits astrocyte inflammatory gene expression through suppression of the proinflammatory miR-155 and miR-155*. Glia. 2011;59:1911-22.

85. Junker A, Krumbholz M, Eisele S, Mohan H, Augstein F, Bittner R, et al. MicroRNA profiling of multiple sclerosis lesions identifies modulators of the regulatory protein CD47. Brain. 2009;132:3342-52.

86. Tili E, Michaille JJ, Cimino A, Costinean S, Dumitru CD, Adair B, et al. Modulation of miR-155 and miR-125b levels following lipopolysaccharide/TNF-alpha stimulation and their possible roles in regulating the response to endotoxin shock. J Immunol. 2007:179:5082-9.

87. Staszel T, Zapala B, Polus A, Sadakierska-Chudy A, Kiec-Wilk B, Stepien E, et al. Role of microRNAs in endothelial cell pathophysiology. Pol Arch Med Wewn. 2011;121:361-6.

88. Kong W, He L, Richards EJ, Challa S, Xu CX, Permuth-Wey J, et al. Upregulation of miRNA-155 promotes tumour angiogenesis by targeting $\mathrm{VHL}$ and is associated with poor prognosis and triple-negative breast cancer. Oncogene. 2014;33:679-89.

89. Lopez-Ramirez MA, Wu D, Pryce G, Simpson JE, Reijerkerk A, King-Robson J, et al. MicroRNA-155 negatively affects blood-brain barrier function during neuroinflammation. FASEB J. 2014;28:2551-65.

90. Wu XY, Fan WD, Fang R, Wu GF. Regulation of microRNA-155 in endothelial inflammation by targeting nuclear factor (NF)-kappaB P65. J Cell Biochem. 2014;115:1928-36.

91. Ashhab MU, Omran A, Kong H, Gan N, He F, Peng J, et al. Expressions of tumor necrosis factor alpha and microRNA-155 in immature rat model of status epilepticus and children with mesial temporal lobe epilepsy. J Mol Neurosci. 2013:51:950-8.
92. Liu DZ, Tian Y, Ander BP, Xu H, Stamova BS, Zhan X, et al. Brain and blood microRNA expression profiling of ischemic stroke, intracerebral hemorrhage, and kainate seizures. J Cereb Blood Flow Metab. 2010;30:92-101.

93. Zhou R, Yuan P, Wang Y, Hunsberger JG, Elkahloun A, Wei Y, et al. Evidence for selective microRNAs and their effectors as common long-term targets for the actions of mood stabilizers. Neuropsychopharmacology. 2009;34:1395-405.

94. Shizu R, Shindo S, Yoshida T, Numazawa S. MicroRNA-122 down-regulation is involved in phenobarbital-mediated activation of the constitutive androstane receptor. PLOS ONE. 2012;7, e41291.

\section{Submit your next manuscript to BioMed Central and take full advantage of:}

- Convenient online submission

- Thorough peer review

- No space constraints or color figure charges

- Immediate publication on acceptance

- Inclusion in PubMed, CAS, Scopus and Google Scholar

- Research which is freely available for redistribution

Submit your manuscript at www.biomedcentral.com/submit
C Biomed Central 